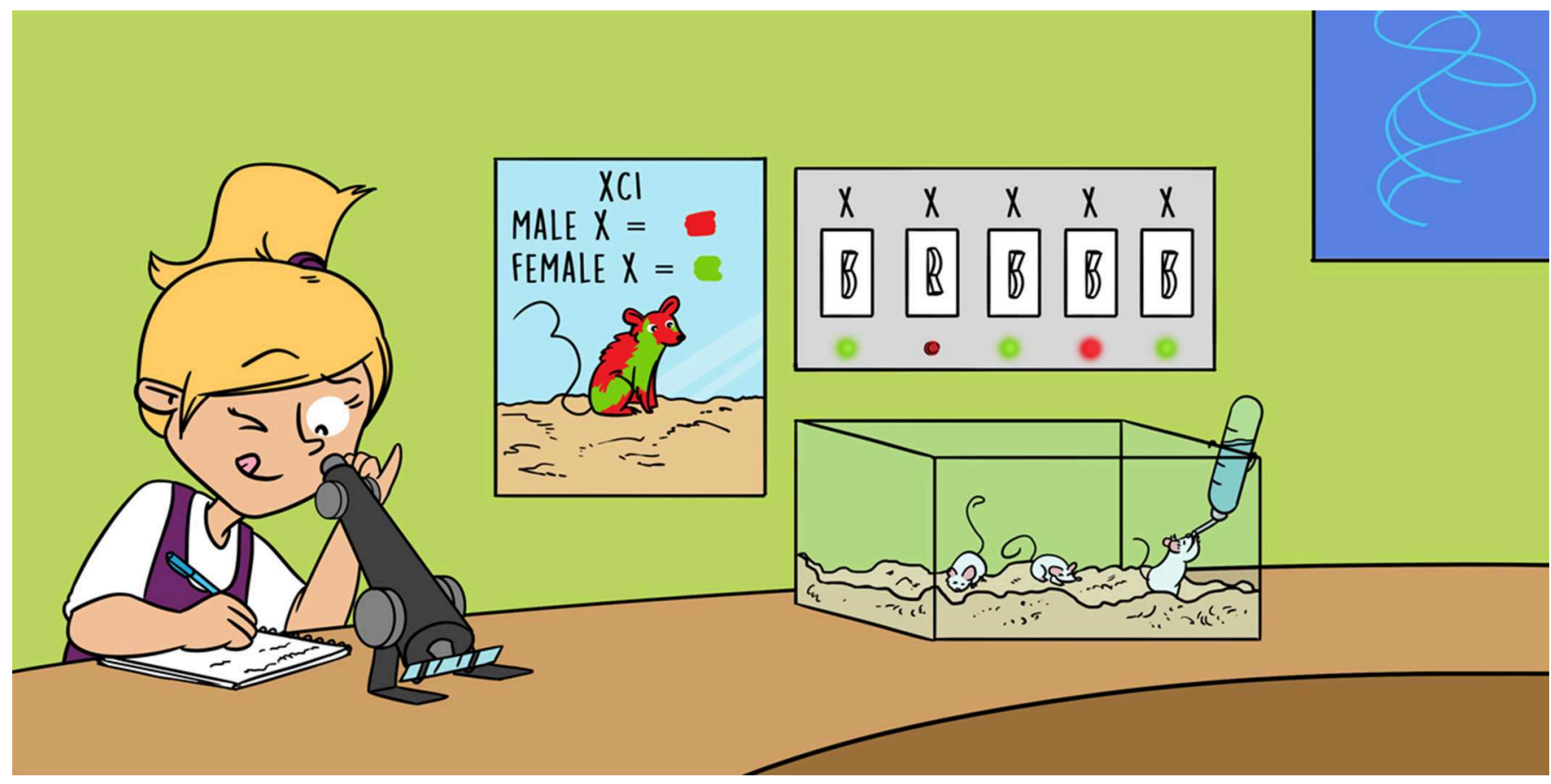

\title{
X MARIKS THE SPOT: HOW X CHROMOSOME INACTIVATION GIVES FEMALES AN ADVANTAGE
}

\section{Sarah Niemi ${ }^{1}$ and Hao $\mathrm{Wu}^{2 *}$}

${ }^{1}$ Department of Behavioral Neuroscience, Northeastern University College of Science, Boston, MA, United States

${ }^{2}$ Whitehead Institute of Biomedical Research, MIT, Cambridge, MA, United States

YOUNG REVIEWERS:

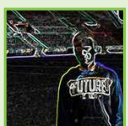

ALEJANDRO

AGE: 14

ANEAL

AGE: 15
Have you ever looked at a calico cat and wondered how it got its multicolored coat? Or have you wondered why more boys than girls are colorblind? The combination of colors in the cat, and the reason some people are more likely to have traits like colorblindness or to get certain diseases, all comes back to one little part of the body, the $\mathrm{X}$ chromosome! Learning more about how our genes make us unique helps scientists understand how we avoid certain diseases. We wanted to know how the $X$ chromosome affects disease in cells. We used mice to study how one of the $X$ chromosomes turns itself off in females and how this process shapes the design of the body, in health and disease.

\section{WHY ARE CHROMOSOMES IMPORTANT?}

Your body is made up of trillions of cells, each containing deoxyribonucleic acid (DNA). DNA is made up of thousands of genes, which are the "instructions" for things like eye color or whether 
Figure 1

On the left is a picture of a typical calico cat. The diagram shows how orange and black fur color genes on either of the $X$ chromosomes result in different fur colors. Male cats only have one $\mathrm{X}$ chromosome, so they are either black or orange. Female cats carrying two orange $X$ chromosomes will be orange and females with two black $X$ chromosomes will be black. However, due to $\mathrm{XCl}$, females carrying one orange and one black X chromosome will have orange and black patches (adapted from Slutz [3]).

SEX CHROMOSOME

A deoxyribonucleic acid (DNA) molecule that codes for a set of genes that determine the sex of an individual ( $X$ and

Y Chromosomes).

$\mathrm{XCl}$

X chromosome inactivation is a biological process where one of the two copies of the $X$ chromosome becomes inactivated in female mammals.

\section{CELLULAR}

MOSAICISM

The presence of cells, in one individual, with different genes or features. Cellular mosaicism is caused by $\mathrm{XCl}$.

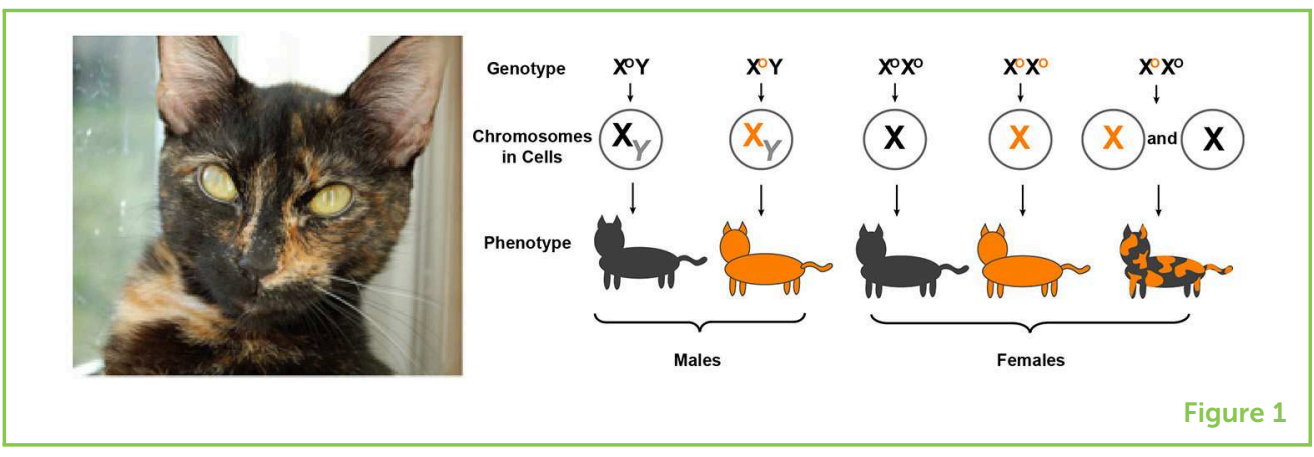

you are more likely to get certain diseases. In your cells, DNA is wrapped tightly into structures called chromosomes. Each human cell has 46 chromosomes, or 23 pairs (since chromosomes come in pairs, with one from your mom and the other from your dad). The 23rd pair of chromosomes are called the sex chromosomes, and those chromosomes are called either $X$ or $Y$. Males have one $X$ sex chromosome and one $Y$ sex chromosome, while females have two $X$ sex chromosomes. The genes on the $X$ chromosomes are important for how the body grows and functions.

\section{WHAT IS X CHROMOSOME INACTIVATION?}

Females have two X chromosomes in each cell! Scientists discovered that, when female babies are developing, they have a special mechanism that randomly turns off one of their two $X$ chromosomes [1]. When one $X$ turns off, the other is still working and its genes can be expressed, which means those traits can show up in the female's body. This process of turning one X chromosome off is called $\mathrm{X}$-chromosome inactivation $(\mathrm{XCl})$. Since not every cell turns off the same $X$ chromosome, the cells can express $X$-chromosome genes differently from each other. This is called cellular mosaicism. Cellular mosaicism gives females more diversity than males, meaning that they have more options during development and more ways to prevent disease [2]. We will describe this more, do not worry!

Imagine a calico cat-they are almost always female. Female calico cats have two versions of a gene for their coat color. Both versions are located on their $\mathrm{X}$ chromosomes. Patches of fur are either orange or black, depending on which $X$ chromosome is turned off in that patch of hair cells. Imagine that the $X$ from the mom carries the orange fur gene, and the $X$ from the dad carries the black fur gene. If one patch on a kitten's back has the mom's X chromosome inactivated, then that patch of fur will be black! But what if some skin cells on a spot on the kitten's tail have the dad's X chromosome inactivated? Those cells will express the orange gene and the fur will be orange (Figure 1). XCI only happens in female mammals, including humans, and affects almost all genes on the $X$ chromosome. 
X-LINKED DISEASE

Genetic diseases in which the disease-causing gene exists on the $\mathrm{X}$ chromosome.

\section{GENE EXPRESSION}

The process by which information from a gene is used to create the physical characteristics of an animal.

\section{WHY IS STUDYING $X$ CHROMOSOME INACTIVATION IMPORTANT?}

Many genes can undergo changes, called mutations, which, in some cases, can make a person more likely to get certain diseases. Diseases caused by mutations in genes on the $X$ chromosome are called $\mathrm{X}$-linked diseases. Remember, males do not experience $\mathrm{XCl}$ because they only have one $X$ chromosome. So, if males have a disease-causing gene on their $\mathrm{X}$ chromosome, it will be active and more likely to cause disease. However, $\mathrm{XCl}$ helps protect females from X-linked diseases. Imagine a girl has a healthy copy of a gene on one $X$ chromosome and a mutant copy of the same gene on her other $X$ chromosome. If the $X$ chromosome with the mutant copy is turned off due to $\mathrm{XCl}$, then the $X$ chromosome with the healthy copy will stay active and express the gene properly. This does not mean she would not get sick, but it will increase her chances of not getting the diseases related to the mutant gene. This is why studying $\mathrm{XCl}$ is important! The patterns of disease gene expression that result from $\mathrm{XCl}$ might determine how severely someone is affected by an $\mathrm{X}$-linked disease.

One example of an X-linked disease is red-green colorblindness. Red-green colorblindness is a disease in which the affected person cannot tell red from green. Another example of an X-linked disease is called Norrie disease, and that is what we studied. Norrie disease affects the eyes and can cause blindness in boys. Interestingly, Norrie disease also affects girls, but more mildly. Norrie disease is caused by a mutation on the $X$-linked gene called norrin. We wanted to understand how XCl affects girls who carry a bad copy of the Norrie disease gene. Knowing these patterns for different diseases can help scientists learn more about why people get sick or stay healthy.

\section{HOW DID WE STUDY X CHROMOSOME INACTIVATION AND NORRIE DISEASE IN OUR EXPERIMENT?}

The pattern generated by $\mathrm{XCl}$ happens to cells everywhere in the female's body very early in development. That means the trillions of cells making up the body all express genes from only one $X$ chromosome or the other. A whole organ, part of a muscle, or a whole side of the brain could have any pattern of expressed "mom X-linked genes" and "dad X-linked genes." That is pretty cool! We wanted to see if patches of cells in a female's body are more "mother expressing" or more "father expressing." Here is how we did it:

We used mice in our experiment, because they are very easy to work with in the laboratory. We used colored dyes to stain the $X$ chromosomes from the mom and the dad in female mice. The "mom $X$ chromosome" was stained green and the "dad X chromosome" was stained red. The red or green dye only stained the $X$ chromosome 
Figure 2

These images were taken using a microscope that can detect the red and green dyes the mouse chromosomes were stained with (adapted from Wu et al. [4]). XCI creates different patterns all over the body. (A) Female mice siblings show different $X$ chromosome inactivation patterns across their entire bodies. (B) XCl creates "patchy" patterns in female skin cells. (C) $\mathrm{XCl}$ creates an uneven pattern in the eye cells (retinas) of a mouse with Norrie disease. The $\mathrm{XCl}$ pattern of left vs. the right retina shows how the severity of the disease can be different between the two eyes.

\section{RETINA}

The inner layer of the eye that is usually sensitive to in most vertebrates. The function of the retina is similar to the film of a camera!
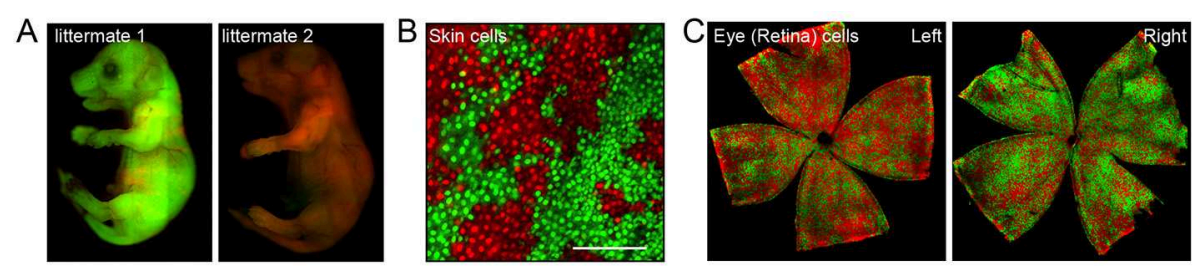

Figure 2

that was working to express genes - the $X$ chromosome that had not been turned off by $\mathrm{XCl}$. We studied healthy female mice and female mice with Norrie disease [4]. We could see the red and green colors in the cells using a special microscope. This told us which cells in the mouse had an active "dad X chromosome" or an active "mom X chromosome." We stained cells all over the mouse, like the heart, the tongue, the skin, and the eyeballs! Looking at cells in the eyeball was especially interesting to us, since Norrie disease affects the eye and causes blindness. After taking pictures of the different body parts, we examined the photos and discussed why these different patterns of $\mathrm{XCl}$ were important to our experiment. The red and green cells in Figure 2 are examples of the cool patterns $\mathrm{XCl}$ can create!

Figure 2 shows some of the results from our experiment. The red and green cells in this figure show how $\mathrm{XCl}$ can be different within one female animal, or between siblings. In Figure 2A, even though these two sisters share the exact same DNA from their parents, one is almost all green and one is almost all red. This means that the green mouse is expressing mostly "mom X chromosome" genes and the "dad $X$ chromosome" genes are almost all inactivated. The red mouse has almost all its "dad X chromosome" genes activated, and the "mom $X$ chromosome" genes inactivated. This is how $\mathrm{XCl}$ can cause diversity between organisms.

Figure $2 \mathrm{C}$ shows the retina of the eyeballs from a female mouse with Norrie disease. You can see that the left retina has a lot of red, meaning that the "dad X chromosome" is very active in that eye. The right retina has a lot of green, so the "mom X chromosome" is active in the green areas, but inactive in places where you see red cells! So, what does this tell us about how $\mathrm{XCl}$ affects Norrie disease? Let us say that the red-stained "dad X chromosome" carries the diseased copy of the Norrie disease gene. This means that, in the cells that are red, the diseased $\mathrm{X}$ chromosome is active and expressing the disease gene. The more cells that express the disease-causing gene, the worse the disease will be! So, from this image, we can see that the left eye is more diseased than the right eye in this mouse. This explains why the disease might only affect one eye in a female patient or might affect both eyes differently. $\mathrm{XCl}$ also explains why two female patients might both have Norrie disease, but one has severe symptoms and blindness, while the 
other has only mild symptoms. This was a very exciting discovery from our experiment.

\section{WHAT ELSE DID WE LEARN ABOUT XCI?}

We also studied how $\mathrm{XCl}$ shapes the female body during development. In our experiment with the mice, we found that sometimes the cells expressing green or red would be evenly scattered (almost like red and green sprinkles on a cupcake). In other areas, the red and green cells formed patches or were symmetrical, as in Figure 2B. We wondered why sometimes the colors were scattered and other times they were in bunches. From our research, we realized that the pattern of $\mathrm{XCl}$ depends on the way each tissue in the body develops. When an animal is growing, some cells, like blood, move all over the body. Others, like skin cells, usually do not move too much during development. This means that blood cells have a chance to mix with each other and have a higher chance of looking like red and green sprinkles. For cells that stay in a certain area, like skin cells, they may share the same inactive $X$ chromosome because they came from the same dividing cell. This leads to the patches of red and green, just like the patchy fur pattern on the calico cat or in the eyes in Norrie disease! Amazingly, the pattern varies even among siblings, which means that even identical twin females will have very different gene expression patterns on the $\mathrm{X}$ chromosomes.

\section{HOW CAN OUR STUDY HELP SCIENCE AND MEDICINE?}

What does this all mean? How can our discovery of the pattern of $\mathrm{XCl}$ in cells help people? Well, we studied a fascinating biological activity that occurs in all female mammals. The technique we used, color-coding the $X$ chromosomes, could be very helpful for scientists researching $X$-linked diseases. We hope that this study inspires others (maybe future scientists, like you!) to look at how XCl affects brain development. It would be interesting to understand how $\mathrm{XCl}$ influences differences in the left and right sides of the brain or whether $\mathrm{XCl}$ causes differences in brain structure between males and females. We believe that learning more about the role $\mathrm{XCl}$ plays in disease will improve our understanding of many diseases. Future research may even inspire a therapy to turn on the inactivated $X$ chromosome, to help females with $\mathrm{X}$-linked diseases.

\section{ORIGINAL SOURCE ARTICLE}

Wu, H., Luo, J., Yu, H., Rattner, A., Mo, A., Wang, Y., et al. 2014. Cellular resolution maps of $X$ chromosome inactivation: implications for neural development, function, and disease. Neuron 81:103-19. doi: 10.1016/j.neuron.2013.10.051 


\section{REFERENCES}

1. Lyon, M. F. 1962. Sex chromatin and gene action in the mammalian X-chromosome. Am. J. Hum. Genet. 14:135-48.

2. Migeon, B. 2006. Females Are Mosaics: X Inactivation and Sex Differences in Disease. Oxford, UK: Oxford University Press.

3. Slutz, S. 2019. X-inactivation Marks the Spot for Cat Coat Color. Science Buddies. Available online at: https://www.sciencebuddies.org/sciencefair-projects/project-ideas/MamBio_p022/mammalian-biology/xinactivation-cat-coat-color (accessed April 19, 2019).

4. Wu, H., Luo, J., Yu, H., Rattner, A., Mo, A., Wang, Y., et al. 2014. Cellular resolution maps of $X$ chromosome inactivation: implications for neural development, function, and disease. Neuron 81:103-19. doi: 10.1016/j.neuron.2013.10.051

SUBMITTED: 28 June 2019; ACCEPTED: 14 November 2019;

PUBLISHED ONLINE: 28 November 2019.

EDITED BY: Kari Merete Ersland, University of Bergen, Norway

CITATION: Niemi S and Wu H (2019) X Marks the Spot: How X Chromosome Inactivation Gives Females an Advantage. Front. Young Minds 7:134. doi: 10.3389/ frym.2019.00134

CONFLICT OF INTEREST: The authors declare that the research was conducted in the absence of any commercial or financial relationships that could be construed as a potential conflict of interest.

COPYRIGHT @ 2019 Niemi and Wu. This is an open-access article distributed under the terms of the Creative Commons Attribution License (CC BY). The use, distribution or reproduction in other forums is permitted, provided the original author(s) and the copyright owner(s) are credited and that the original publication in this journal is cited, in accordance with accepted academic practice. No use, distribution or reproduction is permitted which does not comply with these terms.

\section{YOUNG REVIEWERS}

\section{ALEJANDRO, AGE: 14}

I like science since I was 6 years old. Nowadays, I have an active collaboration with a science group specialized in robotics in an important university near to my town. I find it very interesting and challenging to understand this part of science. I also like biological science and mathematics very much. Apart form this, I love playing football with my friends and I play the trumpet. I go to my grandparents place during the weekends and help my grandpa harvesting the vegetables. 


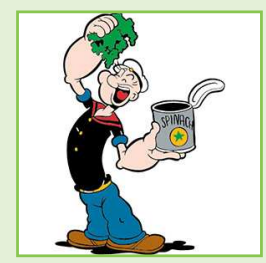

\section{ANEAL, AGE: 15}

I love to push the limits of life itself.

\section{AUTHORS}

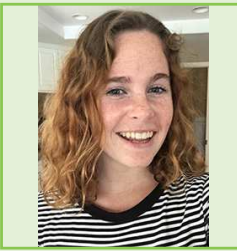

\section{SARAH NIEMI}

Sarah is a senior at Northeastern University studying Behavioral Neuroscience with a minor in Writing. She has incorporated her love for science and writing by publishing several articles in Northeastern's science magazine and writing poetry about mental health. She holds a deep passion for psychiatric research and hopes to eventually achieve a Ph.D. in Neuroscience to pursue a career in research. In her spare time, she loves to bake and paint!

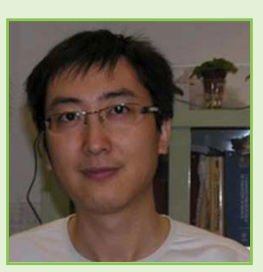

\section{HAO WU}

Dr. Wu obtained his Ph.D. at HKUST. He is a visiting scholar at the Whitehead Institute of MIT where he is interested in harnessing iPSC technology and genome and epigenome editing approaches to establish disease relevant models that are genetically accurate for neurological disorders. He hopes these models will improve the understanding of disease pathomechanisms and help develop potential therapeutic treatments. Previously, Dr. Wu was a post-doctoral fellow at Johns Hopkins University School of Medicine where he executed the study on cellular resolution maps of $\mathrm{X}$ chromosome inactivation. *hwu@ wi.mit.edu 